\title{
DESENVOLVIMENTO DE UMA CRIANÇA COM SÍNDROME DE PATAU EM UM CENTRO DE ATENDIMENTO ESPECIALIZADO EM SURDOCEGUEIRA
}

\author{
DESARROLLO DE UN NIÑO CON SÍNDROME DE PATAU EN UN CENTRO DE \\ ATENCIÓN ESPECIALIZADA EN SURDOCEGUEIRA
}

\section{DEVELOPMENT OF A CHILD WITH PATAU SYNDROME IN A SPECIALIZED CARE CENTER IN DEAFBLINDNESS}

\author{
Carla Cristine Tescaro Santos LINO ${ }^{1}$ \\ Danielle da Silva Pinheiro WELLICHAN ${ }^{2}$ \\ Michelle Maia MENDONÇA ${ }^{3}$
}

\begin{abstract}
RESUMO: Trata-se de um estudo de campo sobre o acompanhamento na evolução do desenvolvimento cognitivo e psicomotor de uma criança com surdocegueira congênita total e Síndrome de Patau, atendida em um Centro de Atendimento Especializado - Surdocegueira no interior do Estado do Paraná. A criança foi identificada como AC para garantir a sua identidade. Objetiva-se descrever o desempenho da criança no ano de 2019 tendo por base a metodologia de Jan Van Dijk utilizada para bebês com surdocegueira em fase pré-linguística. Embora a literatura nos apresente reduzidas possibilidades para essas crianças, verificou-se que o profissional deve acreditar na estimulação precoce e continuada para beneficiar a qualidade de vida da criança e permitir esperança às famílias. Os resultados da metodologia de Jan Van Dijk sugerem ser eficazes no atendimento individual com a criança, que privilegiam recursos alternativos de comunicação.
\end{abstract}

PALAVRAS-CHAVE: Surdocegueira. Educação especial. Síndrome de Patau.

RESUMEN: Este es un estudio de campo sobre el monitoreo de la evolución del desarrollo cognitivo y psicomotor de un niño con sordoceguera congénita total y síndrome de Patau, visto en un Centro de Atención Especializada - Sordoceguera en el interior del Estado de Paraná. El niño fue identificado como CA para garantizar su identidad. El objetivo es describir el desempeño del niño en 2019 basado en la metodología Jan Van Dijk utilizada para bebés con sordoceguera en la fase prelingüística. Aunque la literatura nos presenta posibilidades limitadas para estos niños, se descubrió que el profesional debe creer en la estimulación temprana y continua para beneficiar la calidad de vida del niño y permitir la esperanza de las

\footnotetext{
${ }^{1}$ Universidade Estadual Paulista (UNESP) Marília - SP- Brasil. Professora Bilíngue em SRMI - área Surdez. Doutoranda em Educação no Programa de Pós-Graduação em Educação (UNESP). Participante do Grupo de Pesquisa em Deficiências Físicas e Sensoriais - DeFSen (UNESP/Marília). ORCID https://orcid.org/0000-00024339-7832. E-mail: carlatescaro@yahoo.com.br

${ }^{2}$ Universidade Estadual Paulista (UNESP) Marília - SP- Brasil. Bibliotecária e Pedagoga. Doutoranda em Educação no Programa de Pós-Graduação em Educação (UNESP). Participante do Grupo de Pesquisa em Deficiências Físicas e Sensoriais - DeFSen (UNESP/Marília). ORCID https://orcid.org/0000-0002-6978-7361. Email: dany_unesp@yahoo.com.br

${ }^{3}$ Universidade Estadual do Norte do Paraná (UENP) Jacarezinho - PR - Brasil. Professora de Pós-Graduação no Grupo Rhema Educação. Licenciada em Pedagogia e Ciências Sociais. Especialista em Educação de Jovens e Adultos e Educação Especial. ORCID: https://orcid.org/0000-0002-9894-520X. E-mail: mi.maia@outlook.com
} 
familias. Los resultados de la metodología de Jan Van Dijk sugieren que son efectivos en el cuidado individual de los niños, que favorecen los recursos de comunicación alternativos.

PALABRAS CLAVE: Sordoceguera. Educación Especial. Síndrome de Patau.

ABSTRACT: This is a follow-up field study on the evolution of cognitive and psychomotor development of a child with total congenital deafblindness and Patau Syndrome, attending at a Specialized Care Center - Deafblindness in the interior of the State of Paraná. The child was identified as AC to guarantee the identity. The objective is to describe the child's performance in 2019 based on the methodology of Jan Van Dijk used for babies with deafblindness in prelinguistic phase. Although the literature presents us with limited possibilities for these children, it was found that the professional must believe in early and continued stimulation to benefit the child's quality of life and allow hope for families. The results of Jan Van Dijk's methodology suggest that they are effective in individual care with the child, who favor alternative communication resources.

KEYWORDS: Deafblindness. Special Education. Patau Syndrome.

\section{Introdução}

A área da Surdocegueira foi reconhecida pelo Ministério da Educação, no início do ano 2000, e em 2002, pela Secretaria de Educação Especial do Ministério da Educação, substituída pela Secretaria de Educação Continuada, Alfabetização, Diversidade e Inclusão (SECADI), o que proporcionou avanços e possibilidades para o atendimento de pessoas nessas condições. (BRASIL, 2002).

O reconhecimento do surdocego como indivíduo único é bastante recente. Além disso, embora muito se soubesse sobre as deficiências isoladamente, os estudos não apresentavam resultados, os quais só começaram a surgir quando a pessoa surdocega passou a ser reconhecida como um ser único (FARIAALMEIDA, 2004). Por isso, adotamos a palavra "surdocega" grafada sem o hífen por entendermos, seguindo as ideias de Lagati (1993), que o surdocego apresenta outras dificuldades além daquelas apresentadas pela surdez e pela cegueira, devendo, portanto, ser considerado um indivíduo único. Além disso, a surdocegueira apresenta diferentes graus na perda da audição e visão, o que impossibilita o uso dos sentidos de distância; cria necessidades especiais de comunicação; causa extrema dificuldade na conquista de metas educacionais, sociais, de lazer, para acessar informações e compreender o mundo que o cerca (ALMEIDA, 2007, p. 35).

$\mathrm{Na}$ área educacional, o professor é considerado um Instrutor Mediador e em sua prática deve considerar que resultados podem ser alcançados quando as características individuais são contempladas, conforme Nascimento e Costa (2010, p. 243) citaram, que 
[...] No caso do surdocego, sua condição linguística e sensorial desencadeia a necessidade de obter do sistema de ensino apoio tecnológico e humano que contemple suas necessidades [...] o aspecto tecnológico refere-se aos sistemas que viabilizam o acesso à informação como o display braile também conhecido como linha braile (traduz o conteúdo que está na tela do computador para o sistema braile), entre outros recursos tecnológicos disponíveis no mercado e muitas vezes inacessíveis para o estudante.

O Instrutor Mediador ${ }^{4}$ é considerado também como um recurso de Tecnologia Assistiva $(\mathrm{CAT}, 2007)^{5}$, cuja definição pode ser descrita como uma

[...] área conhecimento, de característica interdisciplinar, que engloba produtos, recursos, metodologias, estratégias, práticas e serviços que objetivam promover a funcionalidade, relacionada à atividade e participação, de pessoas com deficiência, incapacidades ou mobilidade reduzida, visando sua autonomia, independência, qualidade de vida e inclusão social (BRASIL, $2007, \mathrm{~s} / \mathrm{p})$.

Os recursos e equipamentos da Tecnologia Assistiva são também utilizados para alunos com deficiência múltipla sensorial congênita (que ocorre no nascimento da criança ou adquire antes da aquisição de uma língua) com dificuldades de aprendizagem. O Instrutor Mediador promoverá o ensino de comunicações alternativas e proporcionará a mediação entre a pessoa com surdocegueira e ou com a pessoa com deficiência múltipla sensorial e o seu ambiente (MAIA, 2008) permitindo-lhe possibilidades de se comunicar efetivamente com pessoas ao seu redor e receber informações não distorcidas dessas mesmas pessoas.

A considerar a característica do comprometimento parcial ou total dos sistemas sensoriais da visão e audição, a pessoa com surdocegueira apresenta dificuldades no processo acadêmico e pessoal, causados pelo distanciamento, falta de mobilidade e acessibilidade. Nesse cenário, o professor que atua na função de Instrutor Mediador irá estabelecer um elo entre ele, a criança e o conhecimento, por a criança surdocega apresentar necessidades específicas para a sua interação com o meio ambiente de sua convivência, receber e expressar comunicação, além de dificuldades na locomoção. Fatos estes, que podem ser considerados um desafio para a família e profissionais mediadores, já que a criança demonstrará a melhor forma de comunicação para si própria.

Não raramente, a surdocegueira apresenta associações com outras deficiências e síndromes (MONACO, 2004), é o caso do relato a seguir de uma criança que apresenta, além

${ }^{4}$ Conforme explicação, a professora será chamada de Instrutor Mediador ao longo deste texto.

5 Tecnologia Assistiva é uma área do conhecimento, de característica interdisciplinar, que engloba produtos, recursos, metodologias, estratégias, práticas e serviços que objetivam promover a funcionalidade, relacionada à atividade e participação de pessoas com deficiência, incapacidades ou mobilidade reduzida, visando sua autonomia, independência, qualidade de vida e inclusão social (CAT, 2007).

Temas em Educ. e Saúde, Araraquara, v. 16, n. 1, p. 215-231, jan./jun., 2020. e-ISSN 2526-3471. 
da surdocegueira, a Síndrome de Patau associada ao conjunto que define o diagnóstico e ao quadro clínico desta condição.

A primeira ocorrência da Síndrome de Patau foi registrada em meados de 1960, pelo geneticista humano Klaus Patau e pode ser classificada como um "acidente genético" em que há um cromossomo a mais, podendo gerar malformações no sistema nervoso (trissomia do cromossomo 13), que é possível detectar tanto no pré-natal quanto no neonatal e há uma estimativa de 2,5\% dos fetos conseguirem ultrapassar os nove meses de gestação (ROSA et al., 2013; FLEITAS, 2014).

O cariótipo humano considerado normal é formado por um conjunto de cromossomos presentes nas células de um organismo que se refere às características morfológicas dos cromossomos em número, tipos e formas. Na Síndrome de Patau (figura 1), há a presença de três cromossomos no grupo 13, o que pode ocasionar malformações externas e internas (SIERRA-SANTOS, 2001; ZEN et al., 2008; IGNOROSA-NAVA; GONZÁLEZ-JUÁREZ, 2014), causando acometimento de múltiplos órgãos e sistemas.

Figura 1 - Trissomia do cromossomo 13 - Síndrome de Patau

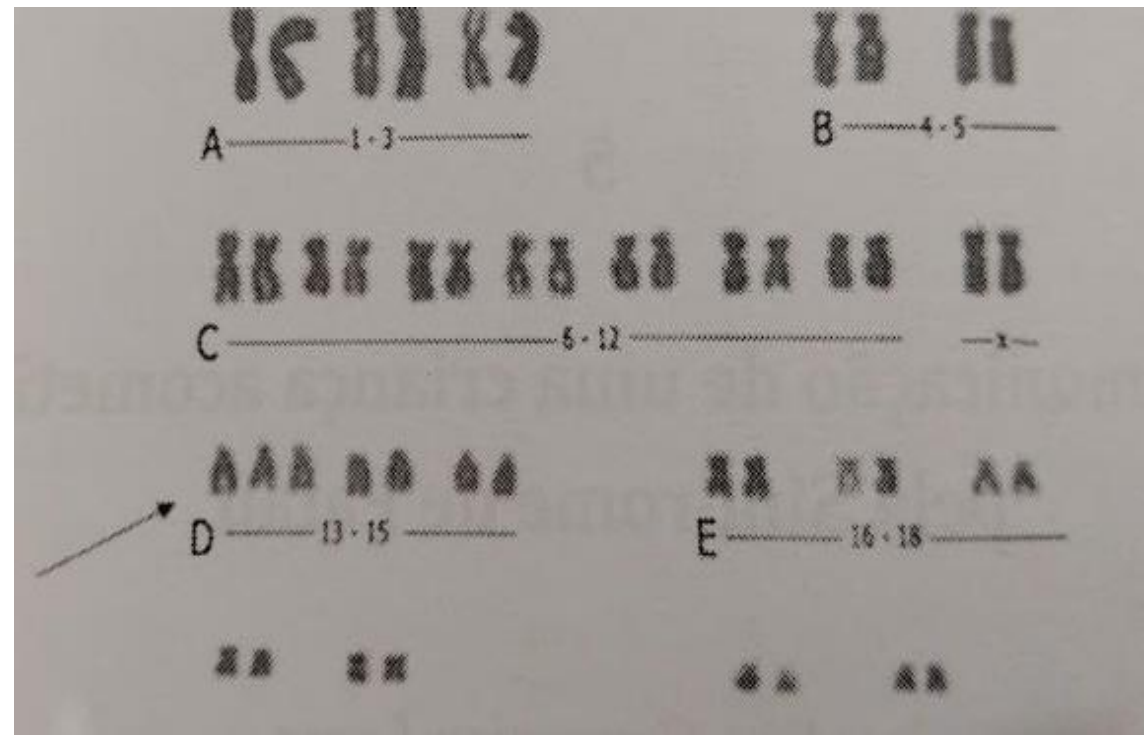

Fonte: Leite (apud LEME; LINO; WELLICHAN, 2019, p. 106)

A cura da Síndrome de Patau ainda é desconhecida, mesmo após tratamentos dos sintomas e intervenções cirúrgicas, mas há relatos de vida até os dez anos (PAZARBASI et al., 2008). Para a família, o diagnóstico é um momento de superação de desafios que poderão ser determinantes para a qualidade de vida de uma criança acometida por essa síndrome.

No caso de AC, foi possível acompanhar seu desenvolvimento desde o nascimento em 2016 e desde então, segue em tratamento e acompanhamento pelos profissionais do Centro de 
Atendimento Especializado em Surdocegueira (CAE-Surdocegueira), no interior do Estado do Paraná, Brasil.

A criança estudo de caso deste artigo, foi atendida no CAE-Surdocegueira (Centro de Atendimento Especializado em Surdocegueira) e apresenta surdocegueira pré-linguística (congênita), ou seja, já nasceu com comprometimento visual e auditivo. Diante dos fatos, tornou-se necessário pensar, pesquisar com profissionais especialistas da área da surdocegueira e discutir um método de comunicação próprio para aqueles que ainda não adquiriram nenhum tipo de linguagem. Assim, há vários métodos para a comunicação de pessoas com surdocegueira, no entanto, a maioria deles necessita que a criança esteja alfabetizada, o que não é o caso de AC com quatro anos e quatro meses em maio de 2020.

Reys (2004) e Viñas (2004) ressaltam que ao nascer ou se tornar surdocega, a primeira medida interventiva e urgente com a criança é buscar um sistema de comunicação funcional, para que a comunicação seja despertada ou estabelecida o quanto antes. Assim, faz-se necessário adequar um meio de comunicação que atenda à característica sensorial da criança surdocega para poder compreender o que ocorre ao seu redor, propondo-lhe condições de se tornar um sujeito ativo e funcional no meio ambiente a que pertence.

No CAE-Surdocegueira, a profissional Instrutora Mediadora inseriu para AC, o primeiro sinal de "mamãe" considerando o que era mais familiar para ela, como o toque, o cheiro e a voz da própria mãe (AC também estava sendo estimulada pela audição, por utilizar o Implante Coclear), podendo facilitar sua compreensão do sinal. Dessa forma, a criança, com o sistema de Libras Tátil, perceberá a articulação, o movimento, o local e a orientação no espaço e no tempo, com informações diversas e poderá construir conceitos e estabelecer comunicação com seus pares. Nesse processo faz-se necessário o conhecimento desse sistema pelo professor mediador para manter uma comunicação eficaz com a pessoa surdocega.

Para que a criança surdocega possa manter diálogo e participação ativa é necessário o empenho da família para continuar em casa, as orientações do profissional Instrutor Mediador do CAE-Surdocegueira, já que a Libras Tátil, para essa criança (AC), é indispensável para o desenvolvimento de sua comunicação.

O texto a seguir, foi elaborado com dados oriundos do relatório de acompanhamento oficial da professora Instrutora Mediadora de AC, no ano de 2019, com a permissão do CAESurdocegueira e dos pais da criança. Todos os procedimentos éticos foram seguidos e as identidades foram preservadas. Foram consultados registros de atendimentos e relatos da família e da profissional que acompanha AC. 
O intuito das autoras é demonstrar por meio da descrição do relato, o trabalho desenvolvido com AC, diagnosticada com a Síndrome de Patau, identificando os desafios e as possibilidades que a criança pode vivenciar quando encaminhada precocemente para atendimentos especializados. Além de reafirmar a necessidade de busca pela qualidade de vida da criança e da família envolvida.

\section{Estudo de caso}

“AC nasceu no mês de janeiro do ano de 2016, com 39 semanas, uma menina, resultado de uma gestação tranquila, planejada e saudável” (LEME; LINO; WELLICHAN, 2019, p. 107). Apresentou uma série de complicações ao nascer, o que a levou para a Unidade de Cuidados Intensivos (UCI), com internação de 25 dias, sendo submetida a diversos exames e com orientação para encaminhamentos específicos na busca de um diagnóstico.

O diagnóstico da Síndrome de Patau foi concluído em 2018 e como consequência, AC não possui visão, audição, apresenta má formação cerebral e rins policísticos. Passou por uma cirurgia no intestino no mesmo ano, teve meningite e para ambos casos, houve internação.

Mesmo diante do diagnóstico da síndrome e das poucas informações existentes sobre o desenvolvimento dela, “[...] o objetivo da família passou a ser a qualidade de vida e a autonomia da filha" (LEME; LINO; WELLICHAN, 2019, p. 109).

Encaminhados ao CAE-Surdocegueira da cidade, os encontros aconteceram duas vezes por semana, as terças e quintas-feiras, com duração de uma hora. A mãe se fazia presente em todos eles, e em alguns momentos a tia também, com as quais a professora Instrutora Mediadora mantinha um bom relacionamento o que auxiliava no processo de continuidade dos trabalhos ali desenvolvidos.

Todas as atividades eram previamente planejadas de acordo com as necessidades e o progresso de AC, e consideravam cuidados específicos para que fossem variados e estimulantes para a aluna. Sempre foram realizadas juntamente com a mãe para que a mesma pudesse dar continuidade ao trabalho em casa, uma vez que as estimulações visuais e auditivas devem ser realizadas diariamente. E especialmente no caso da Libras Tátil, é imprescindível que se trabalhe a palavra em todos os momentos em que a mesma for utilizada, por isso a importância da família nesse processo.

O olho é formado a partir da $4^{\mathrm{a}}$ semana de gestação, com o surgimento e o desenvolvimento dos sulcos ópticos e das vesículas ópticas, encerrados após o nascimento pela mielinização das fibras do nervo óptico expostos à luz (MOORE; PERSAUD, 2000) e a aluna 
AC apresenta na área visual, microftalmia (CID-Q11.2) em ambos os olhos, estruturas oculares formadas, porém, pequenas, globo ocular com diâmetro AXL diminuído, catarata bilateral com neovasos sobre a superfície do cristalino, o que permite apenas a percepção de luz.

Figura 2 - Face dos olhos, o que demonstra diminuição da fenda palpebral

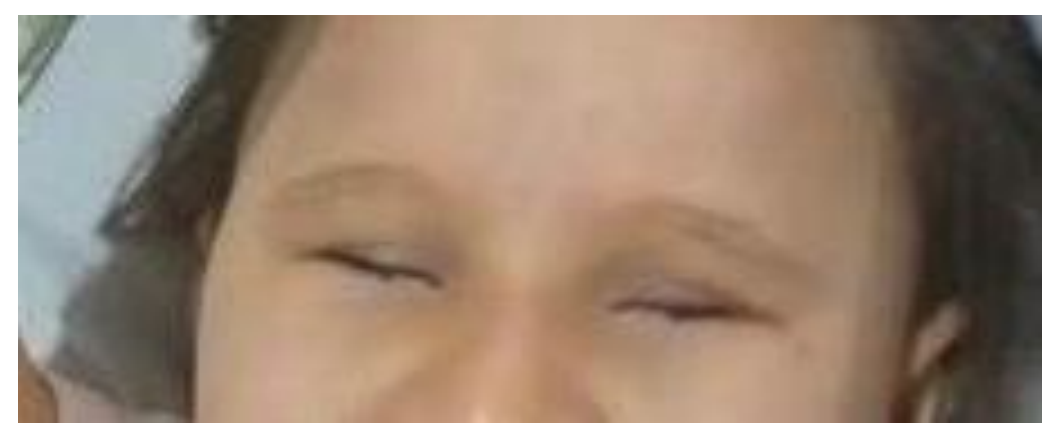

Fonte: acervo das autoras

Na área auditiva, AC apresenta deficiência neurossensorial bilateral (CID H90.3), com Implante Coclear realizado em 2018 na orelha esquerda, ainda em fase de acompanhamento e adaptação no ano de 2019, contudo, já demonstrando possível progresso.

Embasando-se em relatórios elaborados pela professora Instrutora Mediadora dos anos anteriores e ainda, por relatos da mãe e tia, foi possível notar que AC após o período de adaptação do implante, vinha conseguindo realizar atividades que antes não alcançava sucesso, como parar de se movimentar e atentar-se aos sons oferecidos, virar a cabeça para o lado de onde vinha o som e tornar a se virar quando o som mudava de lugar. Quando derrubava um objeto que fazia barulho ao cair, AC se voltava para o lado exato em que o objeto havia caído, na tentativa de pegá-lo, levando as mãozinhas para o local onde o mesmo se encontrava.

AC se enquadra na surdocegueira plus devido a apresentar a Síndrome de Patau, que pode causar atraso mental acentuado, além de malformações graves no sistema nervoso central e nos órgãos internos, além de características físicas muito específicas e frequentes.

As pessoas com surdocegueira podem ter outras deficiências associadas e essa condição foi definida como surdocegueira plus por Mônaco (2004), ou seja, pessoas que nascem com surdocegueira ou foi adquirida e que apresentam associações com deficiência intelectual ou físico-motora e/ou autismo. As necessidades básicas das pessoas com surdocegueira plus continuam sendo as mesmas de uma pessoa com surdocegueira sem outras associações. Mas quando apresentam essas associações, fica evidenciada a importância dos profissionais que mediam a comunicação com essa população conhecerem diferentes formas para interagir e promover o acesso à comunicação, utilizando meios alternativos e/ou ampliados e isso exige desse profissional uma formação ainda mais específica (MOLINA; WATANABE; MAIA, 2018, grifo nosso). 
Em casos de bebês diagnosticados com surdocegueira congênita, como o caso de AC, a metodologia adotada segue a abordagem Van Jan Dijk (1968) que estabeleceu seis fases para o desenvolvimento da linguagem em crianças com surdocegueira que representam uma dinâmica que incorpora estímulos sociais, sequenciais e acumulativos (LEME; LINO; WELLICHAN; 2019), conforme descrito no quadro (Quadro 1) a seguir:

Quadro 1 - Fases para o desenvolvimento da linguagem em crianças com surdocegueira

\begin{tabular}{|c|c|}
\hline FASE 1 - NUTRIÇÃO & $\begin{array}{l}\text { A primeira fase da abordagem coativa. O objetivo dessa fase } \\
\text { é fazer com que a criança permita e aceite um mediador, } \\
\text { cooperando com as atividades pedagógicas propostas por } \\
\text { ele; }\end{array}$ \\
\hline FASE 2 - RESSONÂNCIA & $\begin{array}{l}\text { Consiste na interação de pessoas que agem, se comunicam e } \\
\text { se movimentam na mesma sintonia; }\end{array}$ \\
\hline $\begin{array}{c}\text { FASE } 3 \text { - MOVIMENTO } \\
\text { COATIVO }\end{array}$ & $\begin{array}{l}\text { Ou mão sobre mão - caracteriza-se pela ampliação } \\
\text { comunicativa entre o mediador e a criança, utilizando um } \\
\text { espaço mais amplo; }\end{array}$ \\
\hline $\begin{array}{c}\text { FASE } 4 \text { - REFERENCIA NÃO } \\
\text { REPRESENTATIVA }\end{array}$ & $\begin{array}{l}\text { Utiliza-se um objeto de referência que inicialmente não terá } \\
\text { significado para a criança, no entanto, precisa ser } \\
\text { introduzido antes da realização de qualquer atividade; }\end{array}$ \\
\hline FASE 5 - IMITAÇÃO & $\begin{array}{l}\text { Representa a continuação do movimento coativo, no entanto } \\
\text { é mais rica, pois a criança começa a recriar os elementos } \\
\text { simbólicos assimilados, a fim de conseguir a satisfação de } \\
\text { suas necessidades; }\end{array}$ \\
\hline $\begin{array}{c}\text { FASE } 6 \text { - GESTOS } \\
\text { NATURAIS }\end{array}$ & $\begin{array}{l}\text { A esperança é que a criança seja capaz de iniciar gestos por } \\
\text { sua própria conta. Embora estes gestos sejam muito } \\
\text { concretos, é a primeira tentativa de falar a respeito de algo } \\
\text { que está ausente. }\end{array}$ \\
\hline
\end{tabular}

Fonte: Elaborado pelos autores baseado em Leme, Lino e Wellichan (2019)

Por essa abordagem, sistemas comunicativos alternativos podem auxiliar no desenvolvimento do diagnosticado e a família é elemento essencial para dar continuidade aos trabalhos iniciados no centro especializado. É por meio de movimentos corporais do outro e pelo toque que os sentidos não lesados são estimulados.

No CAE-Surdocegueira a professora Instrutora Mediadora estimulava AC pela abordagem coativa de Van Dijk para a estimulação com movimento do corpo, antecipação, rotina e estimulação visual e auditiva. A respeito do desenvolvimento da linguagem para a aquisição do processamento de sinais sonoros durante as atividades propostas e informações linguísticas.

Em 2016 AC foi submetida a Brainstem Evoked Response Audiometry (BERA) também conhecido como Potencial Evocado Auditivo do Tronco Encefálico (PEATE), que objetiva 
examinar a integridade das vias auditivas, desde a orelha interna até o córtex cerebral. Apresentou cóclea e nervo auditivo menores e malformação no corpo caloso (Agenesia).

Figura 3 - Agenesia total do corpo caloso de AC

Fonte: acervo das autoras

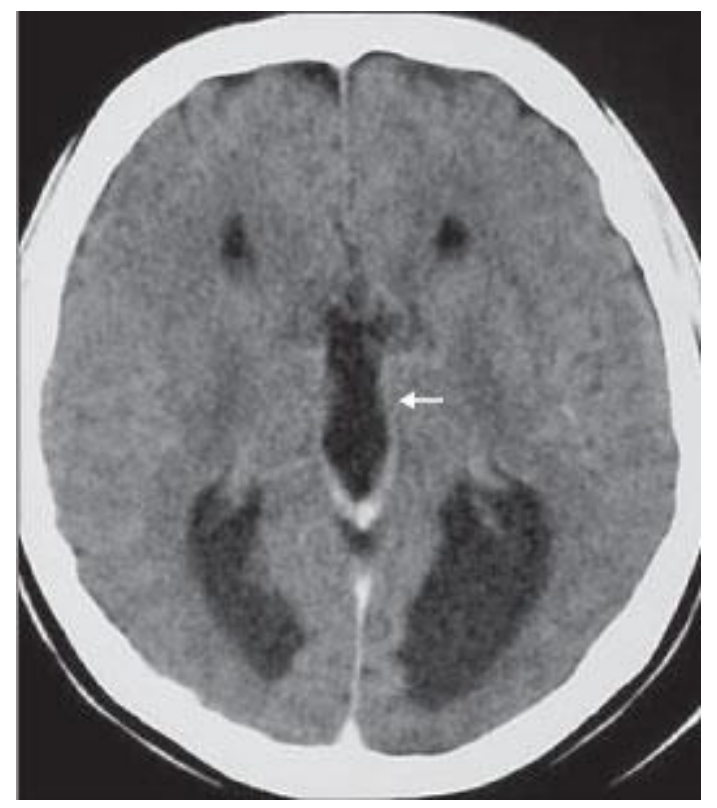

Agenesia do corpo caloso (AgCC) é uma malformação cerebral comum e caracterizada pela ausência (agenesia) do corpo caloso que deveria ter se desenvolvido entre a décima segunda e a vigésima semana de gestação, e pode ser resultante de fatores genéticos ou ambientais. O corpo caloso é responsável pela ligação e comunicação entre os dois hemisférios cerebrais, e provoca no indivíduo epilepsia e atraso no desenvolvimento psicomotor (UTSUNOMIYA et al., 1997).

A ausência do corpo caloso pode ser assintomática durante a vida do ser humano ou com alterações discretas imperceptíveis nos atendimentos clínicos e em exames neurológicos. Pode apresentar-se isoladamente ou associada a outras condições: anomalias estruturais cerebrais (hidrocefalia ou outras), disfunção neurológica (epilepsia, macro ou microcefalia, alterações visuais ou auditivas), malformações extracerebrais, anomalias cromossómicas, e acomete uma criança a cada mil nascimentos. A prevalência de bebês que apresentam agenesia na América do Norte é de 2,3\% e em países latinos é desconhecida (UTSUNOMIYA et al., 1997).

$\mathrm{O}$ atraso do desenvolvimento motor de $\mathrm{AC}$ é fator relevante para a sua reabilitação e para sua capacidade funcional, sendo acompanhada desde 2016 por uma profissional 
especialista na promoção de intervenções e capacitações para a comunicação em pessoas com surdocegueira ou deficiências múltiplas e sensoriais (MAIA, 2008)

Em 2017, AC realizou Ressonância e Reconstrução 3D e foi encaminhada para atendimento em Fonoaudiologia e em 2018, foi submetida à cirurgia de Implante Coclear em hospital especializado em uma cidade do interior de São Paulo.

Após a cirurgia para colocação de Implante Coclear, AC passou por um processo de adaptação, sendo, inclusive, relutante a alguns sons, em alguns momentos no início da adaptação, porém, acabou se adaptando muito bem à sua nova realidade.

Em continuidade aos atendimentos iniciados e relatados em artigo anterior (LEME; LINO; WELLICHAN; 2019) os atendimentos de AC focavam a estimulação auditiva, devido à possibilidade maior que o implante proporcionou na criança. Além disso, devido à frequência nas atividades realizadas no CAE-Surdocegueira, a aceitação para as atividades por parte de AC foi maior, mesmo diante dessa troca da Instrutora Mediadora, que era reconhecida pelo toque sensorial, explorando seu rosto e mãos, aceitando seu contato.

$\mathrm{AC}$ apresenta percepção de luz, como descrito anteriormente e assim, consegue virar a cabeça e os olhos em direção aos objetos iluminados apresentados, fixar o olhar e fazer conexão cerebral com as luzes que vê. É dessa maneira que percebe a luz. Ela consegue elevar as mãos rapidamente ao objeto iluminado ou as estende frente ao rosto como se quisesse tocar a luz ou barrá-la, de acordo com sua intensidade. Porém, só percebe tal luminosidade quando há um grande contraste entre claridade e escuridão ou com objetos iluminados em sala escurecida, pois objetos iluminados em sala com luz natural, AC parece não perceber.

Quando AC pega um objeto nas mãos (figura 4), o que consegue fazer com facilidade, apresenta força e destreza para tal, explora com riqueza de detalhes, passa as mãos por toda a estrutura de cada objeto, nos lados de cima e de baixo ao mesmo tempo, e explora partes de dentro, sempre que encontra uma abertura para colocar as mãos, percebe, inclusive, se é possível colocar as duas mãos dentro do objeto ou apenas uma. Sua destreza com as mãos permite que a aluna explore os objetos sem derrubá-los na maior parte do tempo, segurando com firmeza e segurança. 
Figura 4 - AC em atividades com bolinhas
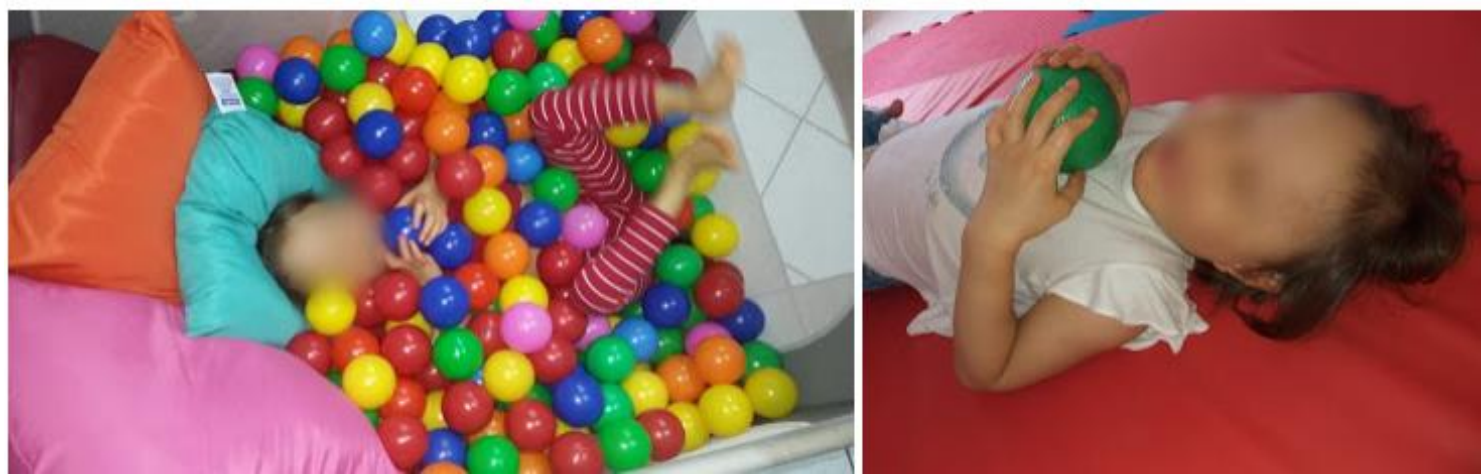

Fonte: acervo das autoras

Quanto às diferentes texturas apresentadas, não somente por meio de objetos e brinquedos, mas de tecidos, tinta, massa de modelar, água, cremes e grãos, AC percebe rapidamente a mudança de uma textura para outra, não mostrando nenhum tipo de relutância por textura alguma, apesar de ter preferência pelas mais suaves, e aparenta gostar de conhecer, reconhecer e explorar objetos.

Em poucos meses, percebeu a pista utilizada pela Instrutora Mediadora para seu reconhecimento, que é um relógio e uma pulseira com dois pingentes no pulso esquerdo, indo de encontro com tal pista sempre que a profissional lhe recebe e lhe cumprimenta na sala, não sendo mais necessário levar suas mãos à pista, pois ao simples toque de mãos, AC já vai de encontro à mesma com facilidade, cumprimentando-a com o toque de mãos.

Ao ouvir a voz conhecida da professora Instrutora Mediadora, AC busca a pista conhecida por ela com facilidade e então explora a pista como costuma explorar os objetos, passando as mãos por todos os lados, em cima, embaixo, balançava os pingentes da pulseira e só após toda essa exploração da pista, ela soltava as mãos da professora, como que esperando pela atividade que viria a seguir.

Além da percepção nas mãos, a aluna também apresenta percepção nos pés, utilizandoos, sempre que possível, para explorar os objetos que a cercam, especialmente quando colocada na piscina de bolinhas, onde sozinha, explora as redes dos arredores do berço com as mãos e os pés, pega e segura as bolinhas e "se afunda" na piscina, virando todo o corpo por entre elas.

AC reconhece a voz da mãe e de outras pessoas importantes em sua vida, com as quais convive por um tempo maior. Às vezes tenta retirar o aparelho do implante. Não é possível precisar ao certo, se o que a incomoda é algum som ou interferência sonora de frequência modulada. 
Existem alguns sons que podem causar interferência no aparelho, como ventiladores, celulares e outros ruídos, ou seja, nesse caso, não seria exatamente o som que a incomoda, mas sim, a interferência causada no aparelho do implante que pode causar sons desagradáveis em seus ouvidos, que pode trazer ruídos à sua audição, ou o simples incômodo físico do aparelho em sua cabeça. Mas quando AC quer que o aparelho seja retirado por algum tempo, ela leva as mãos exatamente ao local que o mesmo se encontra, repetidas vezes, tentando retirá-lo, até que consiga alcançar seu objetivo ou que alguém o retire para ela.

Com facilidade na percepção de sons, AC quando ouve algo, costuma se virar para a direção do som. Gosta de todo tipo de músicas, barulhos e toques sonoros dos brinquedos, o que desperta sua curiosidade sempre que tocado. Produz alguns sons/balbucios da fala, manifestando suas vontades em volume adequado para um diálogo normal, não muito alto, nem muito baixo, o que demonstra que a audição recebida está efetivamente adequada para o seu dia a dia.

No estudo realizado por Cader-Nascimento e Costa (2003, p. 145) as autoras apresentam a importância dos recursos alternativos na busca pela comunicação com surdocegos, e descreveram que é possível

[...] constatar que a aprendizagem de recursos alternativos de comunicação é possível com repercussão nas outras áreas do desenvolvimento humano. Isto leva a afirmar que se o objetivo do trabalho educacional for a comunicação, então a exposição dos surdocegos a todos os recursos possíveis e disponíveis de comunicação é o meio mais viável e promissor para atingir a meta. Se o objetivo da educação for a aprendizagem da linguagem oral, o Tadoma se mostra um método eficiente para alcançar esta meta. No entanto, se o objetivo da educação for sua escolarização, então neste caso, sua exposição a recursos variados e distintos de comunicação pode não ser o melhor caminho. Este fato demanda a realização de pesquisas básicas na busca de novas descobertas.

A equipe médica do hospital onde foi realizado o Implante Coclear e que acompanha o progresso de AC, sugeriu que uma Fonoaudióloga introduzisse o método da Libras Tátil juntamente com seu trabalho fonoarticulatório durante as sessões de fonoterapia da linguagem.

As informações básicas necessárias para a realização de tal trabalho com a criança foram transmitidas inicialmente para a mãe, porém, por falta de tempo hábil, não foi possível a conversa da professora Instrutora Mediadora do CAE-Surdocegueira diretamente com a Fonoaudióloga responsável pelo atendimento de AC, o que deve ocorrer posteriormente, pela profissional (Instrutora Mediadora) que der continuidade a esse trabalho no ano de 2020, pois esta metodologia deve ser trabalhada com enfoque multiprofissional para a colaboração de conhecimentos e troca de informações relevantes ao desenvolvimento de AC. 
Assim, foi iniciada a tentativa de comunicação pela Libras Tátil ${ }^{6}$ com a palavra "mamãe", AC ainda não correspondeu à metodologia, parecendo não ter compreendido ainda tal ideia. Contudo, é importante a insistência nesse tipo de comunicação, pois a princípio é o método que mais se adequa às necessidades e condições de aprendizado da criança.

Figura 5 - Materiais em Libras Tátil utilizados por AC
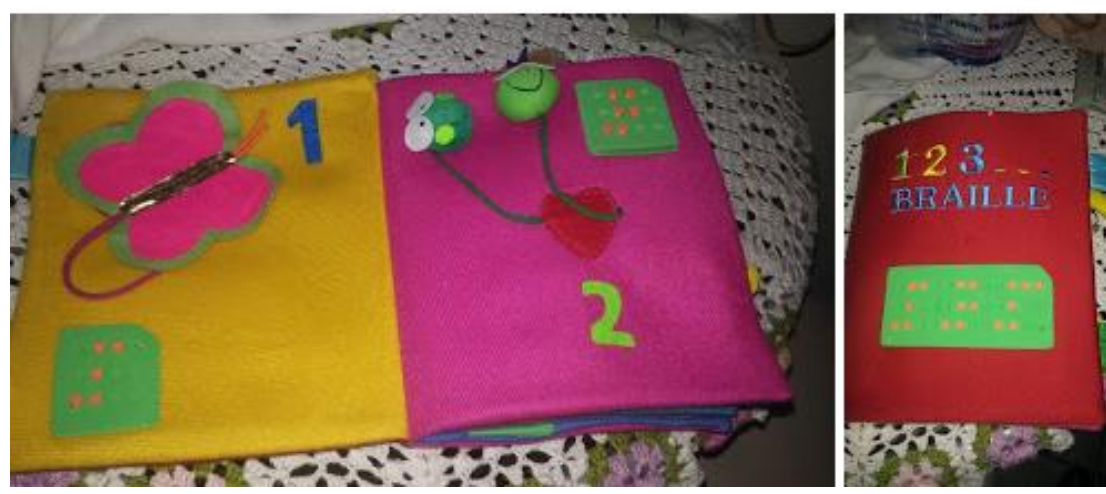

Fonte: acervo das autoras

A Libras Tátil é uma das formas de comunicação utilizadas pelos surdocegos, utilizando-se do tato. Assim como o Tadoma ${ }^{7}$, que também se utiliza do tato, mas este capta o sentido da vibração da voz ao tocar a boca ou o pescoço do Guia-Intérprete. Outro recurso utilizado para a comunicação de surdocegos é o alfabeto manual utilizado para redigir mensagens em Sistema Braille ou o Sistema ou Alfabeto $\mathrm{Moon}^{8}$, que utiliza relevos e o próprio sistema pictográfico que utiliza de símbolos e figuras (MAIA, 2008; GALVÃO, 2013; ALMEIDA, 2017; WATANABE, 2017; ANDRADE, 2018).

Os recursos citados estão sendo apresentados para AC e estudados durante os atendimentos para verificar, na prática, quais alcançam maiores resultados, tendo em vista as particularidades da criança.

Foram recomendados, para 2020, a continuidade de AC nos atendimentos no CAESurdocegueira para a estimulação visual e auditiva, duas a três vezes por semana, por um ou dois horários por vez, de acordo com a disponibilidade da escola e da família, além de manter

${ }^{6}$ Língua de sinais tátil é a adaptação da Libras, utilizada pelos surdos, às pessoas com surdocegueira, por seu uso pelo tato. São sinais realizados em uma ou em ambas as mãos. A posição, orientação e configuração das mãos para a formação dos sinais são as mesmas e altera o espaço de sinalização e a forma de recepção.

${ }^{7}$ Tadoma consiste em um método de linguagem receptiva por meio do tato, ou seja, o surdocego coloca as mãos e o polegar no rosto e na boca da pessoa que estiver falando, o que possibilita interpretar a emissão de sons por meio dos movimentos da boca e das cordas vocais.

${ }^{8} \mathrm{O}$ Alfabeto Moon foi inventado pelo Dr. William Moon, em 1847 na Inglaterra. Consiste na leitura em relevo baseado no alfabeto padrão, com 14 caracteres utilizados em vários ângulos, com contornos nítidos. É considerado mais fácil do que o Braille, e mais utilizado por idosos e pessoas que perderam a visão ao longo da vida.

Temas em Educ. e Saúde, Araraquara, v. 16, n. 1, p. 215-231, jan./jun., 2020. e-ISSN 2526-3471. 
as outras terapias como a Fisioterapia, a Fonoaudiologia, as sessões de Equoterapia e Terapia Ocupacional, além dos acompanhamentos médicos necessários.

\section{Considerações finais}

Embora um dos sintomas da Síndrome de Patau seja a Deficiência Intelectual, AC é uma criança esperta, que aprende e compreende facilmente as atividades propostas, dentro daquilo que lhe é possível entender até o momento, levando-se em conta a surdocegueira e a síndrome.

$\mathrm{AC}$ expressa da sua forma sua opinião sobre o que quer e o que gosta, se fazendo entender com facilidade quando deseja encerrar uma atividade, deitar-se ou ir embora, para isso, meios foram testados e acompanhados para verificar qual forma traria retorno compreensível.

AC representa um caso de superação aos diagnósticos iniciais e aos estudos a respeito da Síndrome de Patau, o que demonstra o quanto os trabalhos de estimulação são importantes e podem trazer qualidade de vida para crianças nessas condições. Mesmo diante de um quadro de surdocegueira agravado pelo diagnóstico de uma síndrome rara, tratamentos, estratégias e recursos precisam ser utilizados e explorados, pois podem trazer resultados satisfatórios e a qualidade de vida tanto de AC quanto da família.

Para os pais, não se pode ignorar os sentimentos causados pelo diagnóstico inicial diante de uma deficiência ou síndrome. Em um misto de sentimentos é preciso vivenciar cada um deles, para poder compreender depois o quanto cada passo (de estímulo ou de busca por profissionais e compreensão sobre o desenvolvimento cognitivo e motor) será importante para a qualidade de vida de seu filho(a) e para toda família.

Com papel fundamental para dar continuidade ao trabalho realizado no CAESurdocegueira, a família precisa ser orientada sobre as melhores formas e estratégias encontradas na literatura ou pela experiência de profissionais durante os atendimentos. Além disso, ela nos fornece informações importantes a respeito do desenvolvimento da criança, uma vez que há ausência de fala de AC e de sistema de comunicação efetivo, situações necessárias a serem trabalhadas por uma equipe multiprofissional, portanto, é preciso um trabalho conjunto e orientador.

Perspectivas mesmo diante de casos como o da AC são necessárias para todos os envolvidos: para a Ciência e os profissionais da saúde, porque instigam novos estudos, procedimentos e descobertas, o que permite que tratamentos sejam ofertados ou testados; para a família, é a oportunidade de amar, conhecer, reconhecer, se comprometer, se envolver e 
"criar" seu(a) filho(a) independentemente do tempo que tenha sido previsto para ele (nas literaturas médicas), em função de seu diagnóstico; para a comunidade de maneira geral, que acompanha casos como o de $\mathrm{AC}$, com possibilidades para reflexão em vários segmentos da sociedade.

O trabalho desenvolvido pela Instrutora Mediadora é de importância singular no processo de desenvolvimento de $\mathrm{AC}$ e desperta pontos importantes a respeito da formação e atuação deste profissional diante de quadros complexos como o de AC. Formação e capacitação associados ao desejo de compreender o que não foi dito são imprescindíveis no processo de estimulação da comunicação.

O desenvolvimento de AC reafirma a necessidade de novos estudos e a busca por novas metodologias e aperfeiçoamentos na área da surdocegueira e em síndromes raras como a de Patau, que é ainda pouco discutida na literatura nacional e internacional.

AGRADECIMENTOS: A família de AC pela oportunidade de acompanhar e registrar seu desenvolvimento.

\section{REFERÊNCIAS}

ALMEIDA, W. G. A guia-interpretação no processo de inclusão do indivíduo com surdocegueira. Educ. rev., Curitiba, n. 65, p. 167-181, set. 2017. Disponível em: https://www.scielo.br/pdf/er/n65/0104-4060-er-65-00167.pdf. Acesso em: 25 maio 2020.

ALMEIDA, C. A. F. A aquisição da linguagem por uma surdocega pré-linguistica numa perspectiva sociocognitivista. Papia: Revista Brasileira de Estudos do Contato Linguístico, v. 17, 2007. Disponível em: http://revistas.fflch.usp.br/papia/article/view/2031/1853. Acesso em: 26 maio 2020.

ANDRADE, A. F. Surdocegueira, cartografia e decolonialidade. Psicol. cienc. prof., Brasília, v. 38, n. 3, p. 595-610, set.2018. Disponível em: https://www.scielo.br/pdf/pcp/v38n3/19823703-pcp-38-3-0595.pdf. Acesso em: 21 maio 2020.

BRASIL. Educação Infantil, saberes e práticas da inclusão: dificuldade de comunicação e sinalização - surdocegueira/múltipla Deficiência sensorial. Brasília, DF: MEC/SEESP. Caderno 5, 2002.

CAT. Comitê de Ajudas Técnicas. Ata da Reunião VII, de dezembro de 2007 do Comitê de Ajudas Técnicas. Secretaria Especial dos Direitos Humanos da Presidência da República (CORDE/SEDH/PR), 2007. Disponível em: http:// http://www.mj.gov.br/corde/comite.asp Acesso em: 02 jun.2020. 
CADER-NASCIMENTO, F. A. A. A.; COSTA, M. da P. R. da. Surdocegueira e a peculiaridade do professor na função de guia-intérprete. Das margens ao centro: perspectivas para as políticas e práticas educacionais no contexto da educação especial inclusiva. Araraquara, SP: Junqueira \& Marin, 2010.

FLEITAS, L. Síndrome de Patau o trisomía 13: reporte de caso. Rev. Nac., Itauguá, v. 6, n. 2, p. 55-60, 2014. Disponível em: http://scielo.iics.una.py/pdf/hn/v6n2/v6n2a06.pdf. Acesso em: 21 maio 2020.

GALVAO, N. C. S. S.; MIRANDA, T. G. Atendimento educacional especializado para alunos com surdocegueira: um estudo de caso no espaço da escola regular. Rev. bras. educ. espec., Marília, v. 19, n. 1, p. 43-60, mar. 2013. Disponível em:

https://www.scielo.br/pdf/rbee/v19n1/04.pdf. Acesso em: 20 maio 2020.

IGNOROSA-NAVA, C. A.; GONZALEZ-JUAREZ, L. Cuidados paliativos para una muerte digna: Estudio de un caso. Enferm. univ., México, v. 11, n. 3, p. 110-116, set. 2014.

Disponível em: http://www.scielo.org.mx/pdf/eu/v11n3/v11n3a6.pdf. Acesso em: 2 jun. 2020.

LEME, C.G.; LINO, C.C.T.S.; WELLICHAN, D.S.P. A comunidade de uma criança acometida pela Síndrome de Patau. In: PAPIM, A. A. P.; ARAUJO, M. A. (Orgs.) O processo de construção da educação para a diversidade: um panorama científico. Porto Alegre: Editora Fi, 2019. Cap.5. p. 105-123.

MAIA, S. R et al. Estratégias de ensino para favorecer a aprendizagem de pessoas com Surdocegueira e Deficiência Múltipla Sensorial: um guia para instrutores mediadores. São Paulo: Grupo Brasil/CIDA, 2008.

MOLINA, K. S. M.; WATANABE, D. R.; MAIA, S. R. Surdocegueira: termos, conceitos e formas de comunicação. In: MANZINI, E. J. et al., (org.). Política d e para educação especial. Marília: ABPEE, 2018.

MÔNACO, C. A mediação para a pessoa com surdocegueira, apostila do curso de Formação de Mediadores, projeto Girassol, Grupo Brasil e Embaixada do Canadá. George Brown College, 2004.

PAZARBASI, A. et al. Prenatal Diagnosis of Translocation 13;13 Patau Syndrome: Clinical Features of two cases. Balkan Journal of Medical Genetics, v. 11, n. 1, p. 69-73, nov. 2008. Disponível em:

https://www.researchgate.net/publication/236210795_Prenatal_Diagnosis_of_Translocation_ 1313_Patau_Syndrome_Clinical_Features_of_Two_Cases. Acesso em: 03 maio 2020.

REYES, D. A. La sordoceguera: uma discapacidad singular. In: REYES D. A. La sordoceguera: um análisis multidisciplinar. Madrid: ONCE, 2004. p. 135-159.

ROSA, R. F. M.; et al. Achados gestacionais, perinatais e familiares de pacientes com síndrome de Patau. Rev. Paul Pediatr, v. 31, n. 4, p. 459-465, 2013. Disponível em: http://www.scielo.br/pdf/rpp/v31n4/pt_0103-0582-rpp-31-04-00459.pdf. Acesso em: 03 maio 2020. 
SIERRA SANTOS, L. et al. Un síndrome de Patau con una supervivencia que supera los pronósticos. Medifam, v. 11, n. 8, p. 70-74, set.2001. Disponível em:

http://scielo.isciii.es/scielo.php?script=sci_arttext\&pid=S1131-

57682001000800009\&lang=pt. Acesso em: 02 maio 2020.

UTSUNOMIYA, H. et al. Dysgenesis of the corpus callosum and associated telencephalic anomalies: MRI. Neuroradiology, n. 39, p. 302-10, 1997. Disponível em:

https://link.springer.com/article/10.1007/s002340050414. Acesso em: 02 maio 2020.

VINÃS P. G. La educación de las personas sordociegas. Diferencias y proceso de mediación. In: REYES D. A. La sordoceguera: um análisis multidisciplinar. Madrid: ONCE, 2004.

WATANABE, D.R. O estado da arte da produção cientifica na área da surdocegueira no Brasil: 1999 a 2015. 2017. 262 f. Dissertação (Mestrado em Educação) - Universidade do Estado de Paulo, USP, SP. Disponível em:

https://www.teses.usp.br/teses/disponiveis/48/48134/tde-13062017-

112304/publico/DALVA_ROSA_WATANABE_rev.pdf. Acesso em: 02 maio 2020.

ZEN, P. R. G. et al. Apresentações clínicas não usuais de pacientes portadores de síndrome de Patau e Edwards: um desafio diagnóstico? Rev. paul. pediatr., São Paulo, v. 26, n. 3, p. 295 299, set. 2008. Disponível em: https://www.scielo.br/pdf/rpp/v26n3/15.pdf. Acesso em: 02 maio 2020.

\section{Como referenciar este artigo}

LINO, Carla Cristine Tescaro Santos; WELLICHAN, Danielle da Silva Pinheiro; MENDONÇA, Michelle Maia. Desenvolvimento de uma criança com síndrome de Patau em um Centro de Atendimento Especializado em Surdocegueira. Temas em Educ. e Saúde, Araraquara, v. 16, n. 1, p. 215-231, jan./jun., 2020. e-ISSN 2526-3471. DOI: https://doi.org/10.26673/tes.v16i1.13743

Submetido em: 02/02/2020

Revisões requeridas: $25 / 04 / 2020$

Aprovado em: 16/052020

Publicado em: 19/06/2020 